\title{
ASSOCIATION OF MYELIN PEPTIDE WITH VITAMIN D PREVENTS AUTOIMMUNE ENCEPHALOMYELITIS DEVELOPMENT
}

\author{
L. A. N. MIMURA, ${ }^{a}$ F. CHIUSO-MINICUCCI, ${ }^{a}$ \\ T. F. C. FRAGA-SILVA, ${ }^{a}$ S. F. G. ZORZELLA-PEZAVENTO, ${ }^{a}$ \\ T. G. D. FRANÇA, ${ }^{a}$ L. L. W. ISHIKAWA, ${ }^{a}$ M. PENITENTI, ${ }^{b}$ \\ M. R. V. IKOMA ${ }^{\mathrm{b}}$ AND A. SARTORI ${ }^{\mathrm{a}}$ * \\ ${ }^{a}$ Department of Microbiology and Immunology, Institute of \\ Biosciences of Botucatu, Univ. Estadual Paulista (UNESP), \\ Distrito de Rubião Junior, Botucatu, São Paulo 18618-970, Brazil \\ ${ }^{\mathrm{b}}$ Flow Cytometry Laboratory - Dr. Amaral Carvalho Foundation, \\ Rua Dona Silvéria, 150, Jaú, São Paulo 17210-070, Brazil
}

\begin{abstract}
Multiple sclerosis is a chronic, inflammatory and demyelinating disease of the central nervous system (CNS). As there is no cure for this disease, new therapeutic strategies and prophylactic measures are necessary. We recently described the therapeutic activity of the association between myelin oligodendrocyte glycoprotein peptide (MOG) and active vitamin D3 (VitD) against experimental autoimmune encephalomyelitis (EAE). The objective of this work was to evaluate the prophylactic potential of this association in EAE. C57BL/6 mice were vaccinated with MOG in the presence of VitD and then subjected to EAE induction. Animals were euthanized 7 and 19 days after disease induction and the following parameters were evaluated: body weight, clinical score, inflammatory process in the CNS, amount of dendritic cells (DCs) and regulatory $T$ cells in the spleen and cytokine production by spleen and CNS cell cultures. Vaccination with MOG associated with VitD determined a drastic reduction in clinical score, body weight loss, CNS inflammation, DCs maturation and also in the production of cytokines by CNS and spleen cell cultures. Collectively, our data indicate that this association prevents EAE development. A similar effect from specific self-antigens associated with VitD is expected in other autoimmune conditions and deserves to be experimentally appraised. (C) 2016 IBRO. Published by Elsevier Ltd. All rights reserved.
\end{abstract}

Key words: multiple sclerosis, experimental autoimmune encephalomyelitis, myelin oligodendrocyte glycoprotein, vitamin D3, tolerogenic adjuvant.

\footnotetext{
${ }^{*}$ Corresponding author. Address:, Department of Microbiology and Immunology, Institute of Biosciences of Botucatu, UNESP - Univ. Estadual Paulista, Distrito de Rubião Junior, Botucatu, São Paulo, 18618-970, Brazil. Tel: +55-14-38800414; fax: +55-14-38153744. E-mail address: sartori@ibb.unesp.br (A. Sartori).

Abbreviations: CFA, complete Freund's adjuvant; CNS, central nervous system; DCs, dendritic cells; EAE, experimental autoimmune encephalomyelitis; Foxp3, forkhead box P3; IFN- $\gamma$, interferon gamma; IL, interleukin; MHC-II, major histocompatibility complex class II; MOG, myelin oligodendrocyte glycoprotein; MS, multiple sclerosis; RPMI, Roswell Park Memorial Institute; TNF- $\alpha$, tumor necrosis factor alpha; Tregs, regulatory T cells; VitD, 1 $\alpha, 25$-dihydroxyvitamin D3.
}

\section{INTRODUCTION}

Multiple sclerosis (MS) is an inflammatory demyelinating disease of the central nervous system (CNS) affecting mainly young people (Ellwardt and Zipp, 2014). According to a recent update, the estimated number of people with MS is 2.3 million worldwide (Browne et al., 2014). Although etiology and immunopathogenesis of this disease are still not entirely elucidated, it is believed that this pathology is mainly mediated by Th1 and Th17 subsets (Sospedra and Martin, 2005; Luchtman et al., 2014). Cytokines such as interferon gamma (IFN- $\gamma$ ), tumor necrosis factor alpha (TNF- $\alpha$ ) and interleukin (IL)-17, produced by these $T$ cell subsets, mediate inflammation and subsequent axonal degeneration, oligodendrocyte death and neuronal dysfunction (Lucchinetti et al., 2000; Sospedra and Martin, 2005; Furuzawa-Carballeda et al., 2007). Defects in the functional activity of regulatory $T$ cells (Tregs) $(\mathrm{CD} 4+\mathrm{CD} 25+)$ have been described in MS patients (Viglietta et al., 2004). Genetic predisposition and environmental factors also contribute to MS initiation and development (Lin et al., 2012; Krementsov and Teuscher, 2013).

Experimental autoimmune encephalomyelitis (EAE) has been extensively used to elucidate the pathophysiology and the potential therapeutic measures applied to MS (França et al., 2014; Zorzella-Pezavento et al., 2014; Rahimi et al., 2015). Current therapeutic approaches to control the destructive immune response in autoimmune disease are mainly based on non-specific drugs that systemically suppress the function of many immune effector cells. This extensive immunosuppression often causes serious and sometimes life-threatening side effects (Damal et al., 2013). Therefore, the need for more specific treatments resulting in lower toxicity and long-term effectiveness is highly desirable. Tolerogenic vaccines comprise a new class of vaccines, designed to re-establish immunological tolerance and thereby theoretically able to reverse autoimmune diseases. Substantial advances have been made in the generation of these vaccines that inhibit EAE in a preclinical setting. Some of the most relevant and recent findings in this context include dendritic cells (DCs) vaccines (van Brussel et al., 2014), myelin oligodendrocyte glycoprotein (MOG)-DNA constructions (Fissolo et al., 2012), cytokine-neuroantigen fusion proteins (Mannie et al., 2012) and polymeric biodegradable lactic-glycolic acid particles loaded with MOG plus IL-10 (Cappellano et al., 2014).

An alternative and very straightforward approach could be based on the concept of tolerogenic adjuvants. 
In contrast to the conventional immunogenic adjuvants that intensify the immune response, the so-called tolerogenic adjuvants have the ability to suppress or modify the specific immune response when associated with specific antigens. This concept and its functional application to induce $\mathrm{T}$ cell tolerance in autoimmune diseases was conceived by Kang et al. (2008). These authors demonstrated that dexamethasone combined with an insulin peptide and FK506 associated with MOG were prophylactic in diabetes and encephalomyelitis, respectively (Kang et al., 2008, 2009). In this context, we hypothesized that active vitamin D3 (VitD) could also behave as a tolerogenic adjuvant if associated with a specific antigen. This possibility was raised by strong evidences that VitD is able to modulate the immune response at both, innate and adaptive levels. It is capable, for example, to promote antimicrobial response by macrophages through the induction of antibacterial proteins (Wang et al., 2004). On the other hand, it suppresses inflammation and promotes immune tolerance by affecting antigen presentation and $\mathrm{T}$ cell proliferation and differentiation (Chun et al., 2014).

In the present study we evaluated if vaccination with MOG in the presence of VitD could be prophylactic and therefore prevent autoimmune encephalomyelitis development. This procedure prevented disease development and triggered reduction in DC maturation, calcium levels were also measured. To determine the effect of $M O G+V i t D$ vaccination strategy in $E A E$ clinical development, mice were first vaccinated with MOG + VitD and then subjected to active induction of EAE (MOG35-55 + Complete Freund's Adjuvant (CFA)). In this case mice were allocated to the following four groups: 1. EAE group (subjected to $E A E$ induction only); 2. MOG/EAE group; 3. VitD/EAE group; 4. $M+V / E A E$ group. Groups 2, 3 and 4 were injected with MOG, VitD or MOG + VitD respectively before EAE induction. Evaluation was performed 19 days after EAE induction, i.e., during the acute encephalomyelitis phase. The following parameters were evaluated: clinical score, body weight and histopathological analysis of the CNS. The effect of vaccination on specific immunity was assessed 7 and 19 days after $E A E$ induction, that is, at the pre-clinical and clinical disease phases, respectively. For this mice were allocated to two groups: 1. EAE group that was subjected to $E A E$ induction and 2. $M+V / E A E$ group that was vaccinated with MOG in the presence of VitD before being subjected to EAE induction. The effect of this vaccination strategy was assessed by cytokine production by spleen cells during pre-clinical and clinical disease phases and also by cytokine production by CNS cells during the clinical disease stage. This experimental design is illustrated below by a timeline scheme.

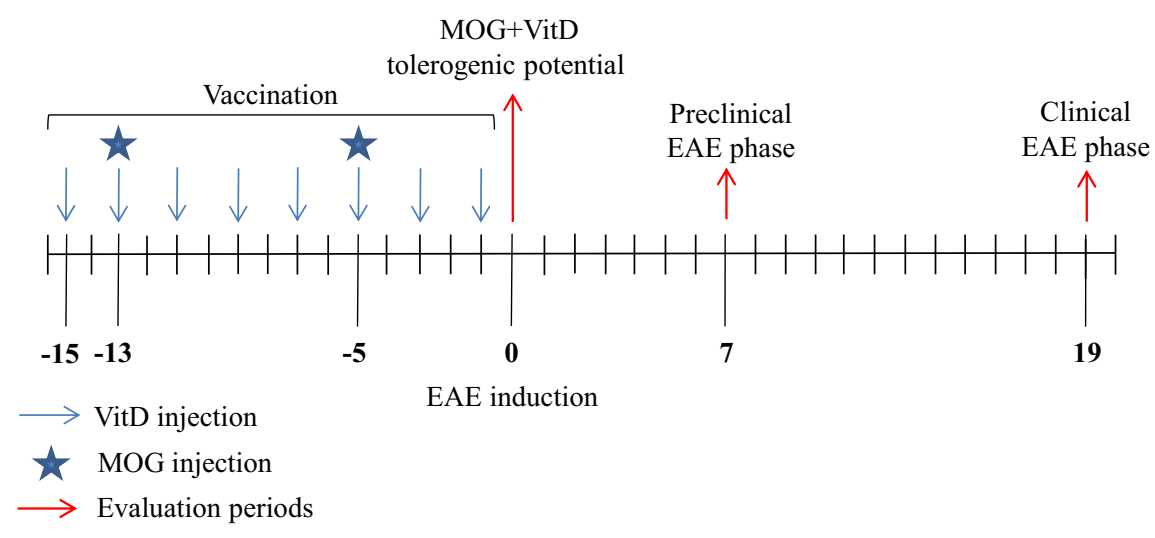

number of Foxp3 + Tregs and proinflammatory cytokine production by spleen and CNS cell cultures. An increased production of TGF- $\beta$ was observed in the spleen and CNS cell cultures.

\section{EXPERIMENTAL PROCEDURES}

\section{Experimental design}

Initially, to assess VitD tolerogenic potential, mice were allocated to four groups: 1. CTL group (negative control group) that received only saline by i.p. route; 2 . MOG group that was injected only with 2 MOG doses $(150 \mu \mathrm{g}$ by i.p. route); 3 . VitD group that was injected only with 8 VitD doses and 4. MOG + VitD group that was injected with both, i.e., 8 VitD doses and 2 MOG doses. VitD tolerogenic potential was tested one day after the last VitD dose and included the evaluation of cytokines, DCs and Tregs determinations. Body weight and serum

\section{Animals}

Female C57BL/6 mice 5-6 weeks old were purchased from University of São Paulo (USP, Ribeirão Preto, SP, Brazil). The animals were manipulated in accordance with the Ethics Committee for Animal Experimentation Institute of Bioscience of Botucatu, Universidade Estadual Paulista (protocol number 571).

\section{Vaccination with MOG in the presence of VitD}

Mice were i.p. injected with $0.1 \mu \mathrm{g}$ of VitD from Sigma (St. Louis, MO, USA), every other day during 15 days (on days $-15,-13,-11,-9,-7,-5,-3$ and -1$)$. On days -15 and -5 the animals were also injected by i.p. route with $150 \mu \mathrm{g}$ of $\mathrm{MOG}_{35-55}$ peptide (MEVGWYRSPFSRVVHLYRNGK) synthesized by Genemed Synthesis Inc. (San Antonio, TX, USA). Mice injected only with VitD or only with MOG were used as 
controls. The rationale used to support this experimental procedure was based on our own experience (ChiusoMinicucci et al., 2015) and also on other author's findings (Lemire and Archer, 1991).

\section{EAE induction}

Mice were subcutaneously injected with $150 \mu \mathrm{g}$ of MOG emulsified with CFA containing $4 \mathrm{mg} / \mathrm{mL}$ of Mycobacterium tuberculosis (Difco, Detroit, MI, USA). Mice also received two intraperitoneal doses, 0 and $48 \mathrm{~h}$ after immunization, of $250 \mathrm{ng}$ of Bordetella pertussis toxin (Sigma). EAE clinical score was daily assessed according to the following criteria: 0 - no disease, 1 limp tail, 2 - weak hind legs, 3 - partially paralyzed hind legs, 4 - complete hind leg paralysis, and 5 - complete paralysis/death.

\section{CNS cell isolation}

Nineteen days after EAE induction, mice were anesthetized with ketamine/xylazine and perfused with $10 \mathrm{~mL}$ of saline solution. To isolate CNS cells, brain and the whole spinal cord were collected and digested with collagenase D $(2.5 \mathrm{mg} / \mathrm{mL}$, Roche Applied Science, Indianapolis, IN, USA) in $4 \mathrm{~mL}$ of Roswell Park Memorial Institute (RPMI) (Sigma) at $37^{\circ} \mathrm{C}$ for $45 \mathrm{~min}$. Then, suspensions were washed in RPMI and centrifuged at $450 \times g$ for $15 \mathrm{~min}$ at $4{ }^{\circ} \mathrm{C}$. Cells were resuspended in percoll (Sigma) $37 \%$ and gently laid over percoll $70 \%$ in tubes of $15 \mathrm{~mL}$. The tubes were centrifuged at $950 \times g$ for $20 \mathrm{~min}$ with centrifuge breaks turned off. After centrifugation the ring containing mononuclear cells was collected, washed in RPMI, and centrifuged at $450 \times g$ for $10 \mathrm{~min}$. Cells were then resuspended in complete RPMI medium, counted, and analyzed.

\section{Cell culture conditions and cytokine quantification}

Spleen and CNS-isolated cells were collected and adjusted to $5 \times 10^{6} \mathrm{cells} / \mathrm{mL}$, and $2.0 \times 10^{5} \mathrm{cells} / \mathrm{mL}$, respectively. Cells were cultured in complete RPMI medium (RPMI supplemented with $10 \%$ of fetal calf serum and $2 \mathrm{mM}$ of glutamine). Spleen cells were restimulated with Con A or MOG $(20 \mu \mathrm{g} / \mathrm{mL}$ and $50 \mu \mathrm{g} /$ $\mathrm{mL}$, respectively) and CNS-isolated cells were restimulated MOG $(50 \mu \mathrm{g} / \mathrm{mL})$. Cytokine levels were evaluated $48 \mathrm{~h}$ later by enzyme-linked immunosorbent assay (ELISA) in culture supernatants using IFN- $\gamma$, TGF- $\beta$ and IL-10 BD OptEIA Sets (Becton Dickinson) and IL-6, TNF- $\alpha$ and IL-17 Duosets (R\&D Systems, Minneapolis, MN, USA). The assays were performed according to the manufacturer's instructions.

\section{Flow cytometry}

Spleen cells were collected and the red blood cells were lysed with buffer containing $\mathrm{NH}_{4} \mathrm{Cl}$. For Tregs analysis, cells were incubated with $0.5 \mu \mathrm{g}$ of FITC labeled antimouse CD4 (clone GK1.5) and $0.25 \mu \mathrm{g}$ of APC-labeled anti-mouse CD25 (clone PC61.5) (eBiosciences, San Diego, CA, USA) for $20 \mathrm{~min}$ at room temperature. Intracellular forkhead box P3 (Foxp3) transcription factor was detected using Foxp3 PE Staining Set (eBiosciences) according to manufacturer's instructions. For DCs analysis, splenic cells were incubated with $0.25 \mu \mathrm{g}$ of FITC-labeled anti-mouse CD11c (clone N418), $\quad 0.03 \mu \mathrm{g}$ of APC-labeled anti-mouse Major histocompatibility complex class II (MHC-II) (clone $\mathrm{M} 5 / 114.15 .2)$ and $0.125 \mu \mathrm{g}$ of PE-labeled anti-mouse CD86 (clone GL1) (eBiosciences) for $30 \mathrm{~min}$ at $4{ }^{\circ} \mathrm{C}$. After incubation, the cells were washed, resuspended in flow cytometry buffer and fixed in paraformaldehyde $1 \%$. The cells were analyzed by flow cytometry using the FACSCanto II (Becton Dickinson, San Jose, CA, USA). Tregs and DCs analyses were performed by FlowJo software (TreeStar, Ashland, OR, USA) and Infinicyt software (Cytognos, Salamanca, Spain), respectively.

\section{Evaluation of inflammatory infiltrates in the CNS}

The histological analysis was performed during EAE acute phase (19 days after EAE induction). After euthanasia, brain and lumbar spinal cord samples were fixed in $10 \%$ formaldehyde and then embedded in paraffin. Paraffin slides $(5 \mu \mathrm{m})$ were stained with Hematoxylin \& Eosin and analyzed with a Nikon microscope.

\section{Calcium level}

The serum calcium level was analyzed using Cálcio Arsenazo III commercial kit (Bioclin, Minas Gerais, Brazil), according to the manufacturer's instruction.

\section{Statistical analysis}

Results were expressed as mean \pm standard deviation or as median and interquartile (25-75\%) ranges. Comparisons between two samples were made by $t$ test and more than two samples were made by a one-way analysis of variance (ANOVA) followed by Tukey's test for parametric variables and by Kruskal-Wallis followed by Dunn's test for non-parametric variables. Chi-square was performed for EAE incidence. Statistical analysis was accomplished with SigmaPlot software version 12.0 (Jandel Corporation, USA) and $p<0.05$ was considered significant.

\section{RESULTS}

\section{Immunomodulatory effect of VitD}

Eight doses of VitD, injected every other day, statistically down-modulated TNF- $\alpha$, IL- 6 and IL-17 production by splenic cells stimulated with Con $A$ as demonstrated in Fig. 1A, B, D, respectively. A downmodulatory effect in the amount of $\mathrm{CD} 11 \mathrm{C}+\mathrm{CD} 86+\mathrm{MHCll}+\mathrm{DCs}$ in the spleen was also elicited by VitD injection (Fig. 1E). On the other hand, mice injected with VitD presented a slightly higher number of CD4 + CD25 + Foxp3 + T cells (Fig. 1F) in the spleen. Body weight (Fig. 1G) and calcium levels (Fig. 1H) were also affected by VitD injection. These animals presented significant hypercalcemia and accentuated body weight loss. The presence of MOG did not affect the VitD downmodulatory effect over IL-6, IFN- $\gamma$ and IL-17. 

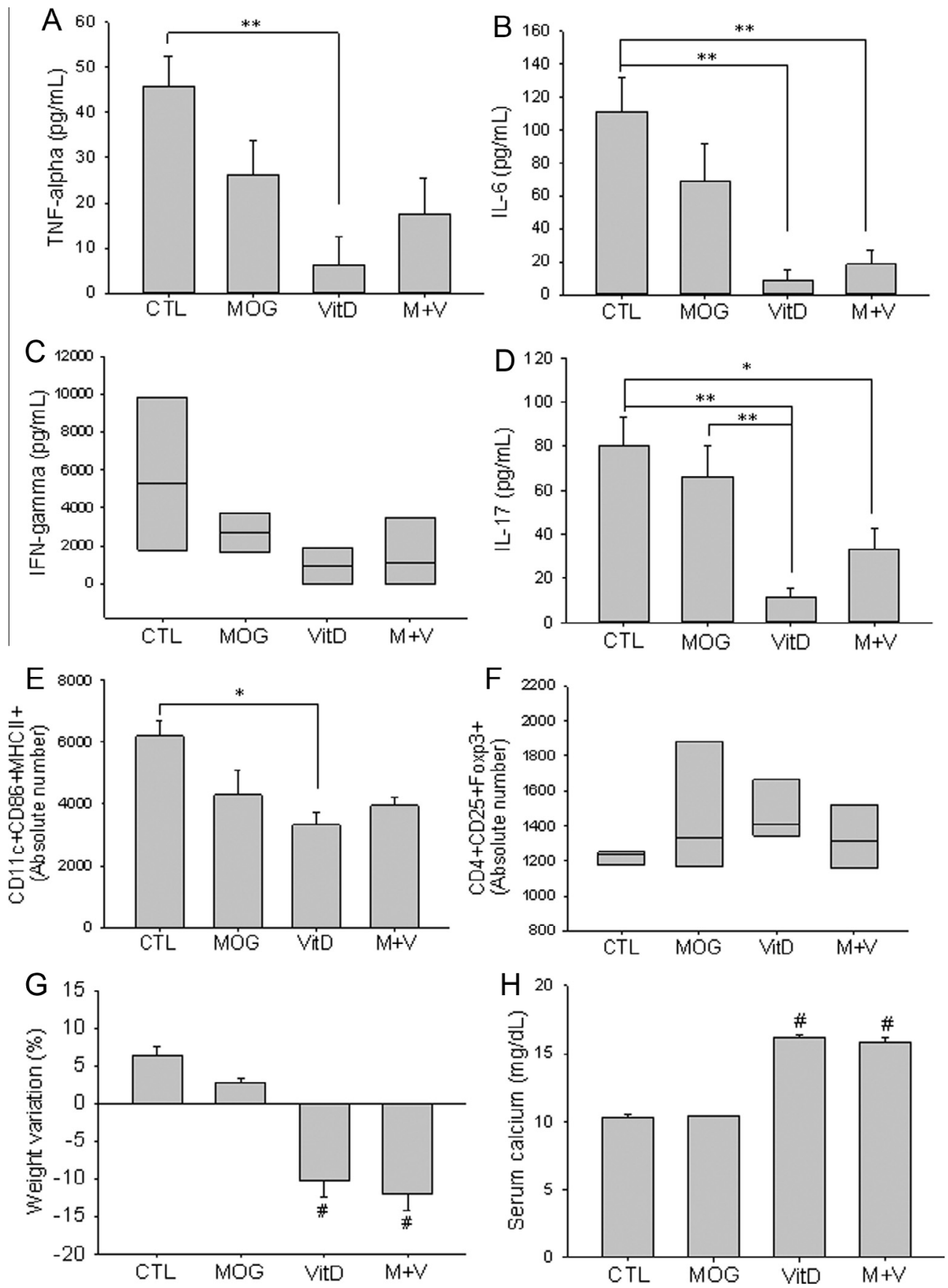

Fig. 1. Immunomodulatory effect of MOG + VitD association in C57BL/6 mice. Mice were injected with MOG + VitD and one day after the last VitD dose the levels of TNF- $\alpha$ (A), IL-6 (B), IFN- $\gamma(C)$ and IL-17 (D) were measured in spleen cell cultures stimulated with Con A. Absolute number of $\mathrm{CD} 11 \mathrm{c}+\mathrm{CD} 86+\mathrm{MHClI}+\mathrm{DCs}(\mathrm{E})$ in total CD11c + cell in 500,000 acquired events and CD4 + CD25 + Foxp3 + Tregs in total CD4 + cell $(F)$ in 100,000 acquired events. Mice were daily weighted $(G)$ and serum calcium levels were measured in the end of vaccination procedure $(H)$. ${ }^{*} p<0.05 ;{ }^{* *} p<0.01$ and ${ }^{\#} p<0.001$ represent comparisons among groups made by one way ANOVA followed by Tukey's test for parametric variables and by Kruskal-Wallis followed by Dunn's test for non-parametric variables. Results were expressed as mean \pm SEM or medians (25$75 \%$, box) of five to six animals per group.

\section{Association of MOG with VitD was highly prophylactic}

To test the prophylactic potential of MOG + VitD association, C57BL/6 mice were vaccinated with MOG in the presence of VitD and then subjected to EAE induction. Disease incidence is shown in Table 1. The incidence in the EAE group reached $85.71 \%$. These animals presented the expected clinical signals as paralysis and accentuated body weight loss, as shown in Fig. 2. Previous vaccination with the MOG + VitD association triggered a clear protection. This group presented no signs of disease as paralysis or body weight loss, as illustrated in Fig. 2B, C, respectively. Differently from this protective effect, VitD or MOG alone slightly delayed clinical disease manifestations (Fig. 2A) 
Table 1. EAE incidence in mice previously immunized with $M O G+V i t D$

\begin{tabular}{lll}
\hline Groups & Incidence (\%) & $p$ value \\
\hline EAE & 85.71 & 0.007 \\
MOG/EAE & 60 & \\
VitD/EAE & 83.33 & \\
$M+V / E A E$ & 0 & \\
\hline
\end{tabular}

and did not affect the maximum clinical score (Fig. 2B) nor prevented the body weight loss (Fig. 2C).
These findings were reinforced by the histopathological analysis. As illustrated in Fig. 3, lumbar spinal cord samples from EAE group (Fig. 3B) presented the expected inflammatory foci concentrated in the tissue periphery. Similar inflammatory infiltrates were observed in samples obtained from MOG/EAE (Fig. 3C) and VitD/EAE (Fig. 3D) groups. Otherwise, no inflammatory infiltrates were detected in spinal cord samples from mice previously vaccinated with MOG associated with VitD (Fig. 3E).
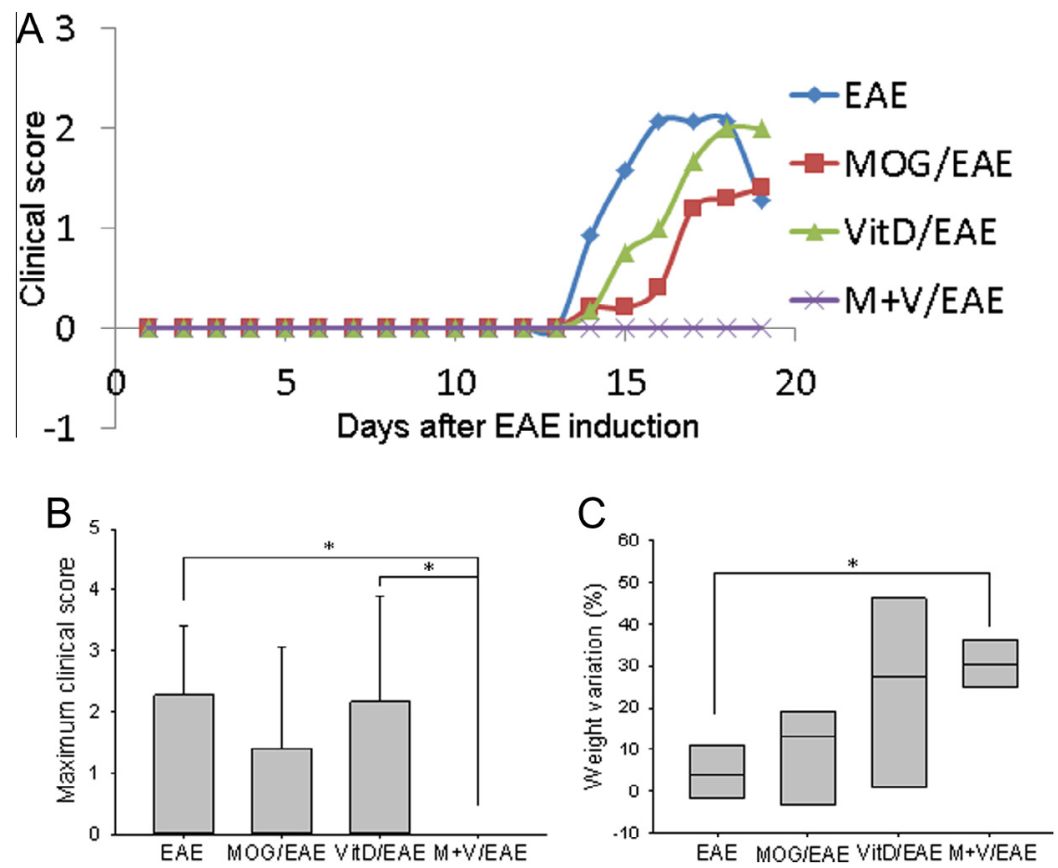

Fig. 2. Effect of $M O G+V i t D$ vaccination before $E A E$ induction. C57BL/6 mice were previously vaccinated with MOG, VitD or MOG + VitD and then submitted to EAE induction. Clinical scores (A), maximum clinical score (B) and body weight variation $(C)$. ${ }^{*} p<0.05 ;{ }^{* *} p<0.01$ and ${ }^{* * *} p<0.001$ represent comparisons among groups made by one way ANOVA followed by Tukey's test for parametric variables and by KruskalWallis followed by Dunn's test for non-parametric variables. Results were expressed as mean \pm SEM or medians (25-75\%, box) of five to six animals per group. Data are representative of two independent experiments.
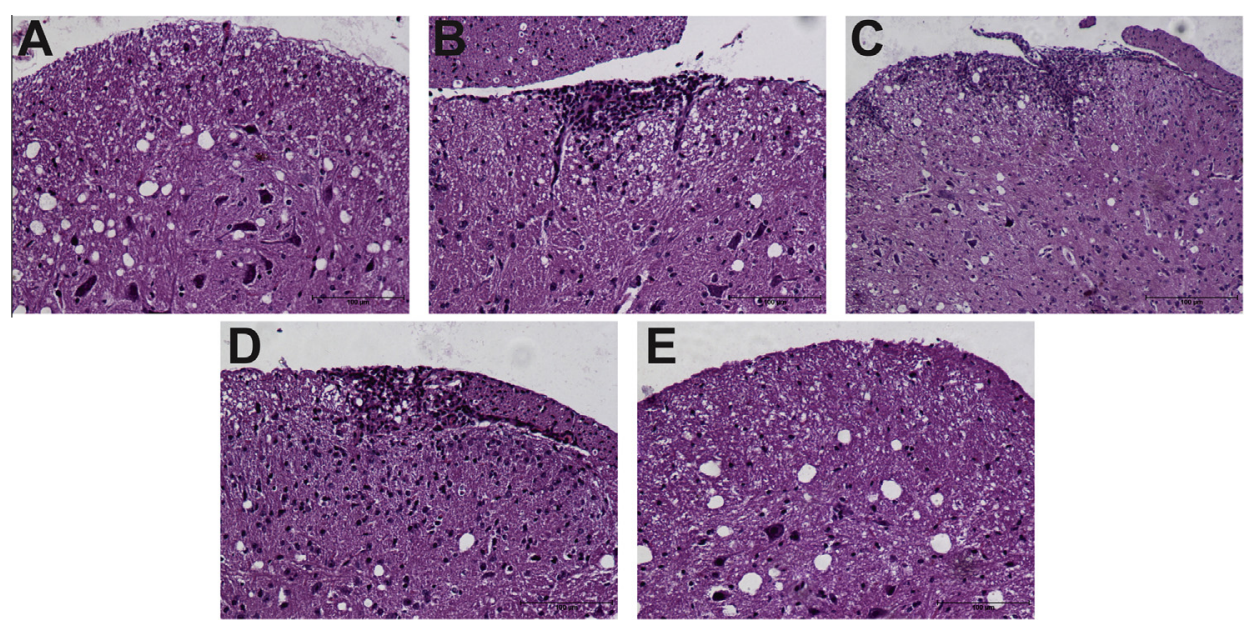

Fig. 3. Inflammatory process in the lumbar spinal cord of C57BL/6 mice vaccinated with MOG + VitD before EAE induction. C57BL/6 mice were previously vaccinated with MOG, VitD or MOG + VitD and then submitted to EAE induction. Euthanasia was performed at the clinical phase to evaluate the presence of inflammatory infiltrates in the lumbar spinal cord. Control (A), EAE (B), MOG/EAE (C), VitD/EAE (D) and M+V/EAE (E) samples. Scale bar $=100 \mu \mathrm{m}$. Micrographs are representative of five animals per group. 

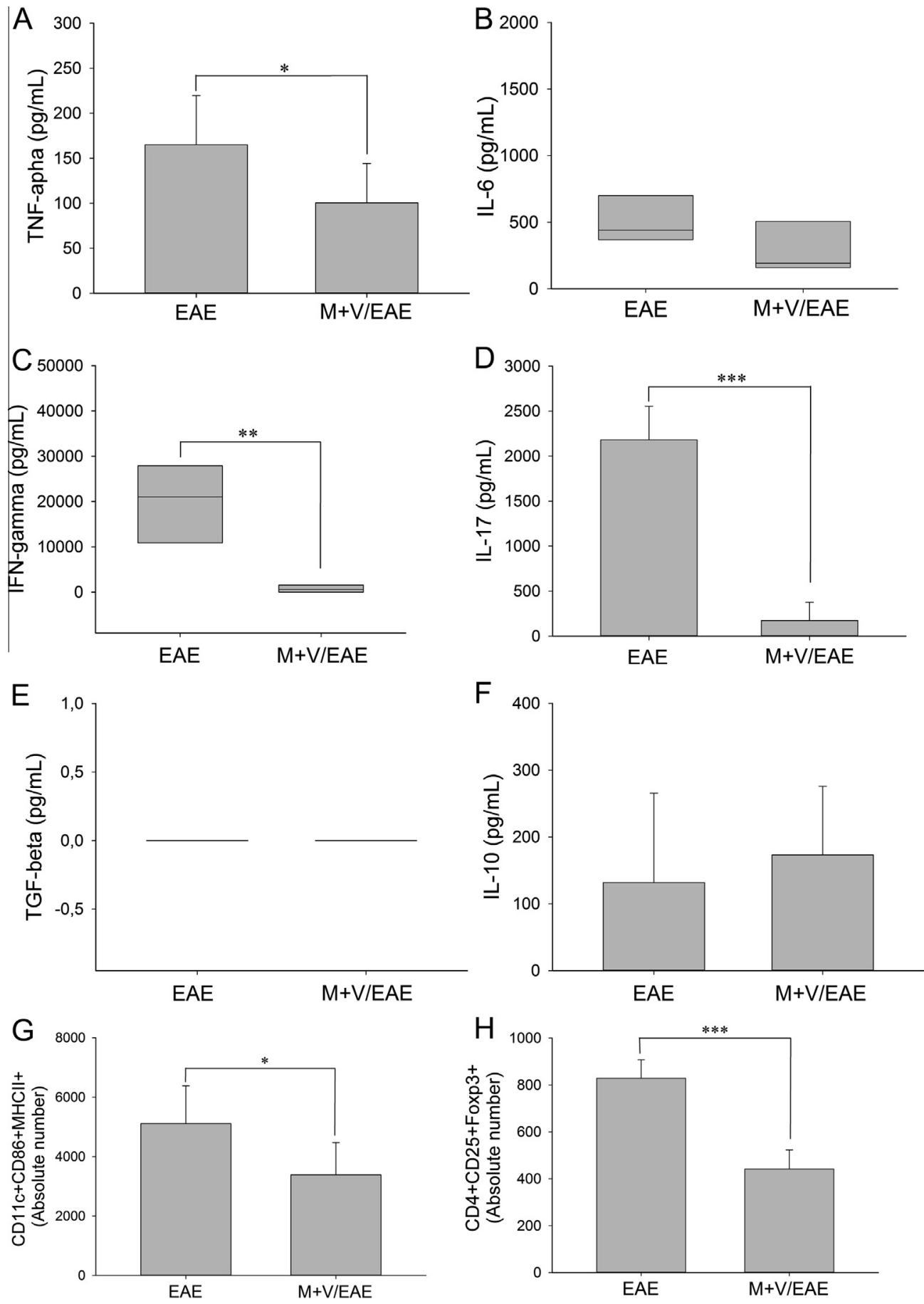

Fig. 4. Effect of $M O G+V i t D$ vaccination before $E A E$ induction in the immune response analyzed during the preclinical disease phase. C57BL/6 mice were previously vaccinated with MOG + VitD and then submitted to EAE induction. After 7 days, TNF- $\alpha$ (A), IL-6 (B), IFN- $\gamma$ (C), IL-17 (D), TGF- $\beta$ (E) and IL-10 (F) levels were measured in spleen cell culture stimulated with MOG. Absolute number of CD11c + CD86 + MHCII + DCs (G) in total CD11c + cell in 500,000 acquired events and CD4 + CD25 + Foxp3 + Tregs in total CD4 + cell $(H)$ in 100,000 acquired events. Comparisons between groups were performed by $t$-test. Data were presented by mean \pm SE or medians $(25-75 \%$ ranges) of six animals per group. * $p<0.05$; ${ }^{* *} p<0.01 ;{ }^{* * *} p<0.001$ represent comparisons between groups performed by $t$-test. Results were expressed as mean \pm SEM or medians $(25-$ $75 \%$, box) of five to six animals per group.

\section{MOG + VitD specific modulatory effect}

The modulatory effect of MOG + VitD previous immunization was evaluated 7 and 19 days after EAE induction, that is, during the preclinical and clinical disease phases, respectively. A very clear downmodulatory activity was observed in the preclinical phase. Splenic cell cultures, derived from vaccinated mice and stimulated in vitro with MOG produced significantly lower amounts of the encephalitogenic cytokines TNF- $\alpha$ (Fig. 4A), IFN- $\gamma$ (Fig. 4C) and IL-17 (Fig. 4D). At this early phase no differences were 

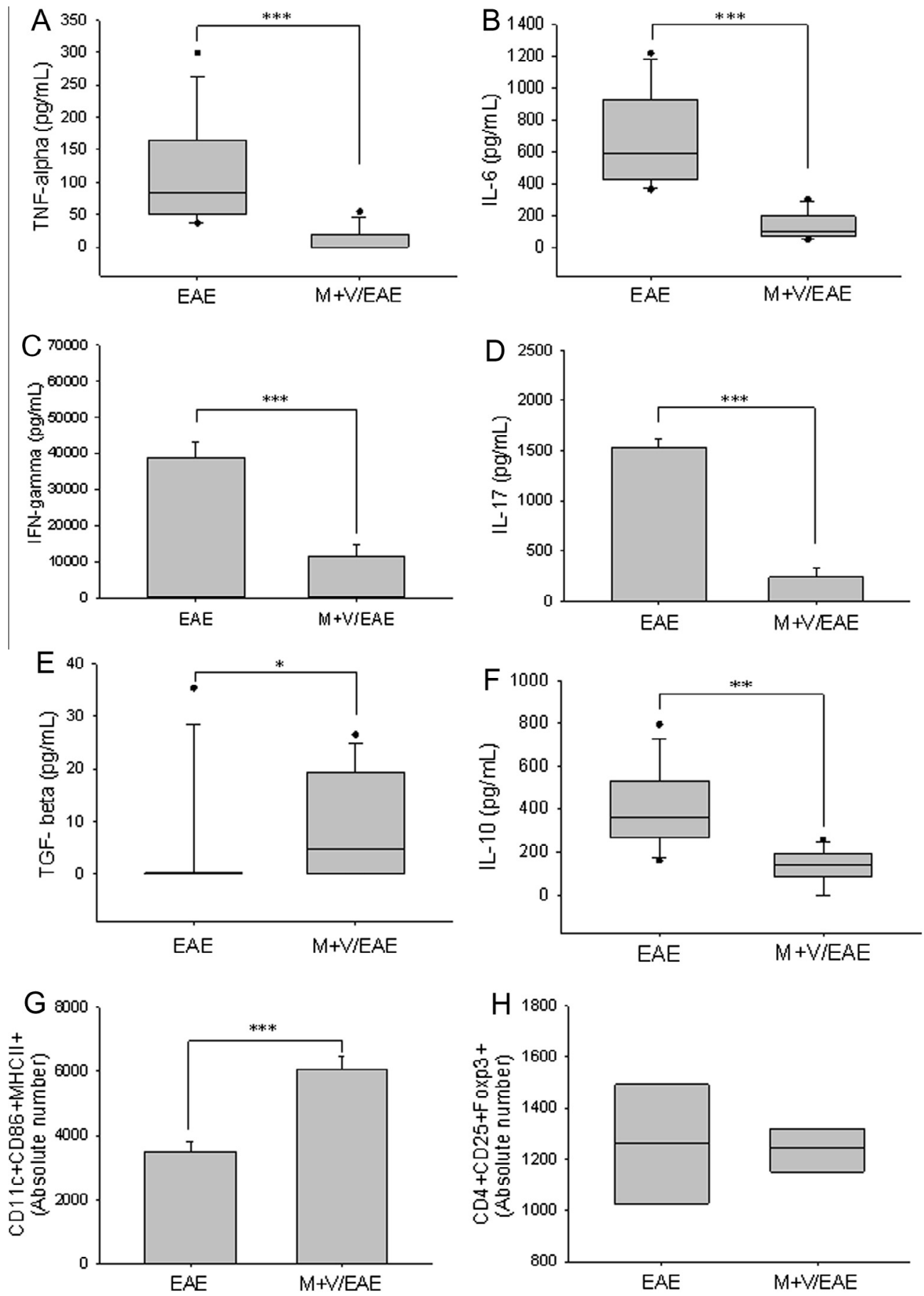

Fig. 5. Effect of $M O G+V i t D$ vaccination before $E A E$ induction in the immune response analyzed during the clinical disease phase. C57BL/6 mice were previously vaccinated with MOG + VitD and then submitted to EAE induction. After 19 days, TNF- $\alpha$ (A), IL-6 (B), IFN- $\gamma$ (C), IL-17 (D), TGF- $\beta$ $(E)$ and IL-10 (F) levels were measured in spleen cell culture stimulated with MOG. Absolute number of CD11c + CD86 + MHCII + DCs $(G)$ in total CD11c + cell in 500,000 acquired events and CD4+CD25+Foxp3 + Tregs in total CD4 + cell (H) in 100,000 acquired events. " $p<0.05$; ${ }^{* *} p<0.01$ and ${ }^{* \star *} p<0.001$ represent comparisons between groups performed by t-test. Results were expressed as mean \pm SEM or medians (25$75 \%$, box) of 12 animals per group. Data are representative of two independent experiments.

observed in the production of TGF- $\beta$ and IL-10 by EAE and $M+V / E A E$ groups, as illustrated in Fig. 4E, F, respectively. Vaccinated animals also presented significantly lower numbers of CD11+CD86 + MHCII+ DCs and CD4 + CD25 + Foxp3 + Tregs in the spleen as depicted in Fig. 4G, H, respectively.
The production of TNF- $\alpha$ (Fig. 5A), IL-6 (Fig. 5B), IFN- $\gamma$ (Fig. 5C) and IL-17 (Fig. 5D) remained significantly lower in the MOG + VitD vaccinated group during the clinical disease phase. However, other parameters were clearly distinct from the ones observed in the previous phase. This was the case of TGF- $\beta$ (Fig. 5E) whose production 
was significantly higher in the previously vaccinated group and IL-10 (Fig. 5F) whose production was decreased in the vaccinated group. Interestingly, there was an increased number of mature DCs in this group even though the number of CD4 + CD25 + Foxp3 + cells was similar in both groups, as shown in Fig. 5G, $\mathrm{H}$, respectively.

\section{Changes in the CNS}

Brain histological analyses confirmed the spinal cord findings, that is, typical inflammatory foci, with a mononuclear predominance, were detected in the $E A E$ control group (Fig. 6A), whereas no inflammatory infiltrates were found in previously vaccinated mice (Fig. 6B). However, enough cells were recovered from the CNS of previously vaccinated mice to allow their in vitro restimulation with MOG. Comparison of cell numbers eluted from the CNS of both experimental groups is shown in Fig. $6 \mathrm{C}$ and clearly indicates that the absolute number of cells was significantly smaller in vaccinated mice. TNF- $\alpha$ (Fig. 6D), IL-6 (Fig. 6E), IFN- $\gamma$ (Fig. 6F), IL-17 (Fig. 6G) and IL-10 (Fig. 6H) production was significantly down-regulated in the previously vaccinated group. On the other hand, a high level of TGF- $\beta$ was observed in the vaccinated group (Fig. 6I).

\section{DISCUSSION}

The main objective of this work was to evaluate if vaccination with MOG in the presence of VitD could be prophylactic in the EAE model. We initially evaluated the immunomodulatory effect of MOG + VitD association in C57BL/6 mice that is a widely accepted strain to develop EAE. This procedure did not affect the number of Tregs but slightly decreased the amount of mature DCs. It also decreased the production of encephalitogenic cytokines, this effect being highly significant in the case of IL-6 and IL-17. Similar immunomodulatory effects have been attributed to VitD alone in C57BL/6 and other mice strains (Chang et al., 2010; Joshi et al., 2011). As most of VitD effects were preserved when MOG was included in the procedure, we tested if MOG + VitD was able to prevent EAE. Previous immunization with $\mathrm{MOG}+\mathrm{VitD}$ association was highly protective and this experimental group presented no clinical disease manifestations, that is, no body weight loss nor paralysis signs. MOG triggered a discrete protective effect characterized by a lower disease incidence and also a delayed paralysis appearance. VitD alone was not protective. The histopathological analysis of the CNS confirmed these findings showing no inflammatory infiltrates in the previously vaccinated group. To the best
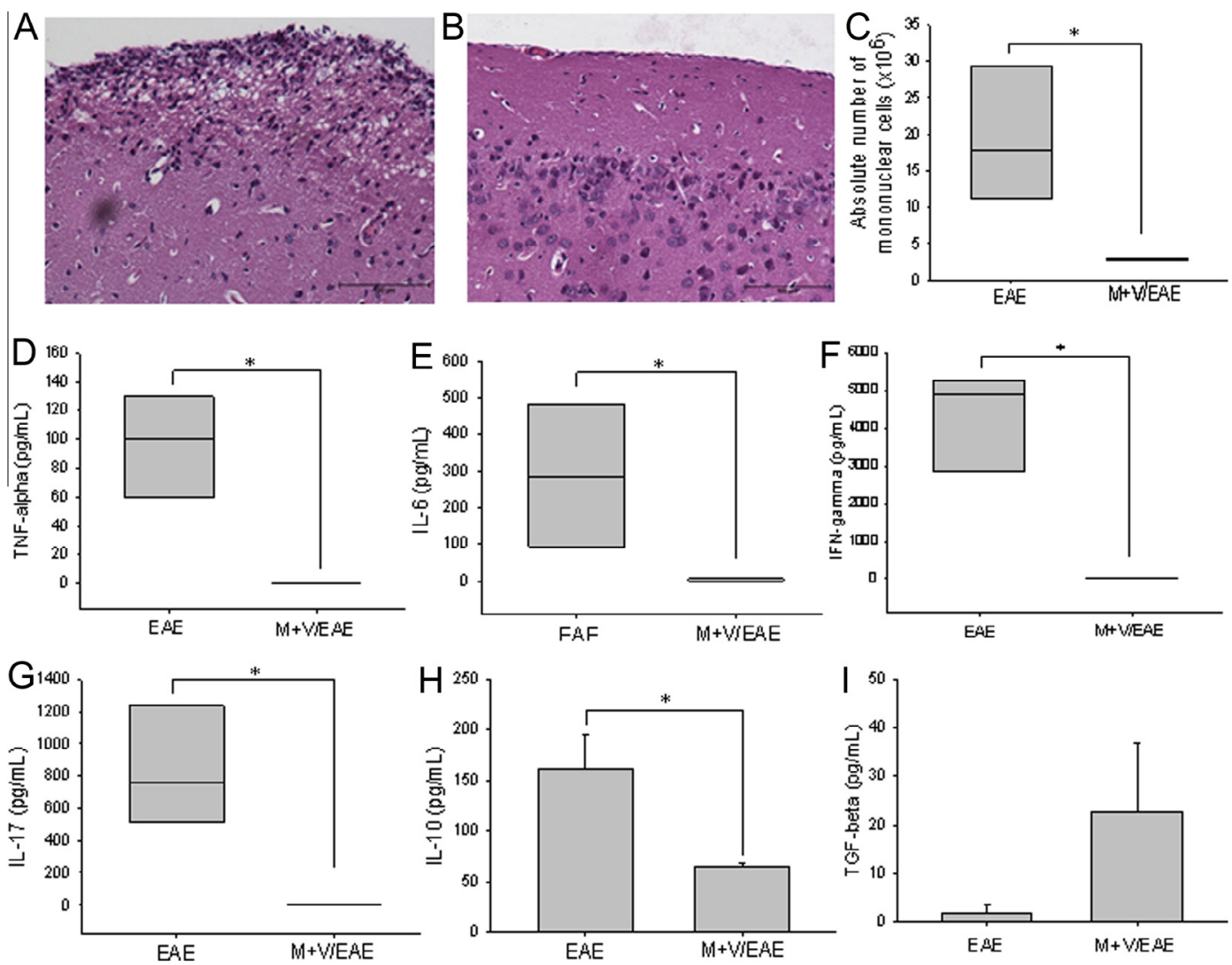

Fig. 6. Effect of MOG + VitD vaccination before $E A E$ induction in the CNS. C57BL/6 mice were previously vaccinated with $M O G+V i t D$ and then submitted to EAE induction. 19 days after EAE induction, brains were collected for histopathological analyses: EAE (A) and M + V/EAE samples (B). Scale bar $=100 \mu \mathrm{m}$. Number of mononuclear cells eluted from the CNS (C). TNF- $\alpha$ (D), IL-6 (E), IFN- $\gamma(\mathrm{F})$, IL-17 (G) and IL-10 (H), TGF- $\beta$ (I) levels were measured in CNS cell cultures stimulated with MOG. ${ }^{*} p<0.05 ;{ }^{* *} p<0.01$ and ${ }^{* * *} p<0.001$ represent comparisons between groups performed by $t$-test. Results were expressed as mean \pm SEM or medians $(25-75 \%$, box) of four pools (each pool contains brains and spinal cords from three animals) per group in CNS cultures. Data are representative of two independent experiments. 
of our knowledge, this is the first demonstration that MOG + VitD association can determine such a strong prophylactic activity in a MS experimental model. The knowledge that purified self-antigens are able to induce specific tolerance in this or other autoimmune diseases is not new. A plethora of strategies employing MOG have been devised and tested and showed promising results. Levy Barazany et al. (2014) described reduction in both, clinical score and CNS inflammation in non-obese diabetic mice after nasal administration of MOG. MOG was also effective when delivered as a genetic vaccine (Fissolo et al., 2012), as a portion of a fusion protein (Divekar et al., 2011) and as mannan-conjugated myelin peptides (Tseveleki et al., 2015). Nonetheless, the use of VitD as a tolerogenic adjuvant when associated with a specific antigen is a new proposition in the autoimmunity field that was recently suggested by us in a therapeutical context (Chiuso-Minicucci et al., 2015) and that is now being also proposed in a prophylactic scenario.

To get some insights into the immunological mechanism involved in this prophylactic effect, parameters usually affected by tolerogenic strategies as cytokines, DCs and Tregs were evaluated. These analyses were done during preclinical and clinical EAE phases, that is, at 7 and 19 days after EAE induction, respectively. A protective effect was already detected at the preclinical phase. By this time vaccinated animals were already producing smaller amounts of encephalitogenic cytokines upon in vitro stimulation with MOG. The similar production of IL-10 and the absence of TGF- $\beta$ production by both groups, suggest that the lower levels of the encephalitogenic cytokines in the protected group were not due to an increased production of anti-inflammatory cytokines at this period. Interestingly, a smaller number of mature (CD11C $+\mathrm{CD} 86+\mathrm{MHCll}+$ ) DCs was detected in the vaccinated group in comparison to the non-vaccinated one. As it is well established that mature DCs are fundamental to promote a strong and effective immune response (Guermonprez et al., 2002), the smaller amount of mature DCs in the spleen of previously vaccinated mice could explain, at least partially, the weak immune response against MOG. This finding is especially relevant because DCs have been pointed as a critical and promising target in the immunomodulatory strategies devised to control autoimmune-mediated diseases (Kavousanaki et al., 2010; Segovia-Gamboa et al., 2014).

The concept that CD4+CD25+Foxp3+ Tregs are deeply involved in the control of autoimmune inflammatory processes is strongly supported by the literature (Smigiel et al., 2014). In addition, most of the therapeutical procedures involving the application of VitD, promoted an increased frequency of this type of Treg (Jeffery et al., 2009; Takeda et al., 2010). For these reasons an increased number of CD4 + CD25+Foxp3 + $T$ cells was expected in the group previously vaccinated with MOG + VitD. However, the number of these cells was significantly lower in this experimental group during the preclinical disease phase. Even though initially not expected, this finding is compatible with the observation that expansion of specific Treg depends upon the presence of proinflammatory cytokines (Korn et al., 2007). Also, a reduced expansion of encephalitogenic T cells without a concomitant increase in the number of Treg cells was associated with the therapeutical effect of atorvastatin in an MS experimental model (Weber et al., 2014). Also supporting our findings, human Treg express VitD receptor and their proliferation in response to IL-2 is inhibited by this vitamin (Khoo et al., 2011). In this scenario, it is possible that this prophylactic effect has been, at least partially, mediated by the presence of immature DCs. Several studies revealed that vitamin D has strong immunomodulatory potential including the capacity to induce tolerogenic/immature DCs. A plethora of in vitro findings indicate the possible benefit of VitD in autoimmune diseases, specially through APCs profile modulation (Farias et al., 2013; Ferreira et al., 2014; He et al., 2014). Our findings suggest that similar effects can be triggered by in vivo injection of VitD.

The lower production of pro-inflammatory cytokines in vaccinated mice was also observed later, during the clinical disease phase. Besides, a clear change was detected in the profile of TGF- $\beta$ and IL-10 production. Previously vaccinated mice produced less IL-10 but higher TGF- $\beta$ levels than the EAE control group. The number of cells eluted from the CNS of previously vaccinated mice was strikingly smaller, confirming, therefore, the histopathological analysis that showed no inflammatory infiltrates in the CNS of this experimental group. In addition, these cells produced TGF- $\beta$ and IL10 but not proinflammatory cytokines in response to MOG. This finding suggests that the MOG + VitD prophylactic effect could be associated with the generation and subsequent infiltration of antiinflammatory cytokine producer $\mathrm{T}$ cells, mainly IL-10 and TGF- $\beta$, to the CNS. A similar beneficial role has been attributed to these two cytokines in other therapeutical scenarios. For example, Taher et al. (2008) demonstrated that these cytokines played a critical role in the protective effects of combined immunotherapy with allergen plus VitD in a mouse model of allergic asthma. Spach et al. (2006) described that IL-10 signaling is essential for VitD-mediated inhibition of EAE. Also, patients with MS that received VitD showed significantly higher levels of these two cytokines compared with the control group (Mosayebi et al., 2011).

The protective effect of this vaccination strategy depended upon the concomitant presence of MOG and VitD because these substances, isolatedly, were not able to induce a significant prophylactic activity. These results also suggest that VitD is working as a tolerogenic adjuvant. The possible role of immunosuppressive drugs as tolerogenic adjuvants was only recently reported. Kang et al. (2008), for example, demonstrated that ovalbumin peptide (323-339) sensitized BALB/c mice could be desensitized by a concomitant treatment with this ovalbumin peptide plus dexametasone. This tolerogenic activity was associated with a blockage of DC maturation. These authors also showed that dexametasone could be tolerogenic and prophylactic in non-obese diabetic mice when associated with an insulin peptide. Kang et al. (2009) demonstrated that this concept also worked in EAE. 
Immunization with MOG-DNA vaccine in the presence of FK506 prevented disease development in mice.

The most promising aspect raised by this work is to reveal that combinations of specific antigens plus tolerogenic adjuvants can be highly prophylactic and possibly therapeutical for autoimmune diseases. We recently described that the early treatment with MOG + VitD of mice submitted to EAE induction was able to control disease development (Chiuso-Minicucci et al., 2015). Further preclinical investigations including tests with VitD analogs devoid of side effects (Leyssens et al., 2014) and more acceptable routes for self-antigen administration, as transdermal or oral ones (Majewska et al., 2007) are mandatory. The persistence of the therapeutic or prophylactic effect of this association and the efficacy of other CNS peptides also requires detailed investigation.

\section{CONCLUSION}

Association of MOG with VitD significantly downmodulated the specific immune response and prevented EAE development suggesting that VitD can be used as a tolerogenic adjuvant.

Acknowledgments-The authors wish to thank the National Council of Technological and Scientific Development (CNPq Brazil) for the financial support (\#grant: 302710/2013-2) and the Coordination for the Improvement of Higher Education Personnel (CAPES - Brazil) for the Mimura LAN scholarship.

LANM, FCM and AS were the main investigators of this study. TFCFS contributed to the experiments and processed the CNS samples for histological analyses. SFZP, TGDF and LLWI contributed with the immunological experiments. MP and MRVI performed cytometric analyses.

\section{REFERENCES}

Browne P, Chandraratna D, Angood C, Tremlett H, Baker C, Taylor BV, Thompson AJ (2014) Atlas of multiple sclerosis 2013: a growing global problem with widespread inequity. Neurol 83:1022-1024.

Cappellano G, Woldetsadik AD, Orilieri E, Shivakumar Y, Rizzi M, Carniato F, Gigliotti CL, Boggio E, Clemente N, Comi C, Dianzani C, Boldorini R, Chiocchetti A, Renò F, Dianzani U (2014) Subcutaneous inverse vaccination with PLGA particles loaded with a MOG peptide and IL-10 decreases the severity of experimental autoimmune encephalomyelitis. Vaccine 32:5681-5689.

Chang JH, Cha HR, Lee DS, Seo KY, Kweon MN (2010) 1,25Dihydroxyvitamin D3 inhibits the differentiation and migration of $T$ $(\mathrm{H}) 17$ cells to protect against experimental autoimmune encephalomyelitis. PLoS One 5:e12925.

Chiuso-Minicucci F, Ishikawa LL, Mimura LA, Fraga-Silva TF, França TG, Zorzella-Pezavento SF, Marques C, Ikoma MV, Sartori A (2015) Treatment with vitamin D/MOG association suppresses experimental autoimmune encephalomyelitis. PLoS One 12: e0125836.

Chun RF, Liu PT, Modlin RL, Adams JS, Hewison M (2014) Impact of vitamin $D$ on immune function: lessons learned from genomewide analysis. Front Physiol 5:151.

Damal K, Stoker E, Foley JF (2013) Optimizing therapeutics in the management of patients with multiple sclerosis: a review of drug efficacy, dosing, and mechanisms of action. Biologics 7:247-258.

Divekar RD, Haymaker CL, Cascio JA, Guloglu BF, Ellis JS, Tartar DM, Hoeman CM, et al. (2011) T cell dynamics during induction of tolerance and suppression of experimental allergic encephalomyelitis. J Immunol 187:3979-3986.

Ellwardt E, Zipp F (2014) Molecular mechanisms linking neuroinflammation and neurodegeneration in MS. Exp Neurol 262:8-17.

Farias AS, Spagnol GS, Bordeaux-Rego P, Oliveira CO, Fontana AG, de Paula RF, Santos MP, Pradella F, Moraes AS, Oliveira EC, Longhini AL, Rezende AC, Vaisberg MW, Santos LM (2013) Vitamin D3 induces IDO + tolerogenic DCs and enhances Treg, reducing the severity of EAE. CNS Neurosci Ther 19:269-277.

Ferreira GB, Gysemans CA, Demengeot J, da Cunha JP, Vanherwegen AS, Overbergh L, Van Belle TL, Pauwels $F$, Verstuyf A, Korf H, Mathieu C (2014) 1,25-Dihydroxyvitamin D3 promotes tolerogenic dendritic cells with functional migratory properties in NOD mice. J Immunol 192:4210-4220.

Fissolo N, Costa C, Nurtdinov RN, Bustamante MF, Llombart V, Mansilla MJ, Espejo C, Montalban X, Comabella M (2012) Treatment with MOG-DNA vaccines induces CD4+CD25 + FoxP3 + regulatory $\mathrm{T}$ cells and up-regulates genes with neuroprotective functions in experimental autoimmune encephalomyelitis. J Neuroinflammation 9:139.

França TG, Chiuso-Minicucci F, Zorzella-Pezavento SF, Ishikawa LL, da Rosa LC, Colavite PM, Marques C, Ikoma MR, da Cunha Mde L, Sartori A (2014) Previous infection with Staphylococcus aureus strains attenuated experimental encephalomyelitis. BMC Neurosci 9:15-18.

Furuzawa-Carballeda J, Vargas-Rojas MI, Cabral AR (2007) Autoimmune inflammation from the Th17 perspective. Autoimmun Rev 6:169-175.

Guermonprez P, Valladeau J, Zitvogel L, Thery C, Amigorena S (2002) Antigen presentation and T cell stimulation by dendritic cells. Annu Rev Immunol 20:621-667.

He X, Yan J, Zhu X, Wang Q, Pang W, Qi Z, Wang M, Luo E, Parker DM, Cantorna MT, Cui L, Cao Y (2014) Vitamin D inhibits the occurrence of experimental cerebral malaria in mice by suppressing the host inflammatory response. J Immunol 193:1314-1323.

Jeffery LE, Burke F, Mura M, Zheng Y, Qureshi OS, Hewison M, Walker LS, Lammas DA, Raza K, Sansom DM (2009) 1,25Dihydroxyvitamin D3 and IL-2 combine to inhibit T cell production of inflammatory cytokines and promote development of regulatory $\mathrm{T}$ cells expressing CTLA-4 and FoxP3. J Immunol 183:5458-5467.

Joshi S, Pantalena LC, Liu XK, Gaffen SL, Liu H, Rohowsky-Kochan C, Ichiyama K, Yoshimura A, Steinman L, Christakos S, Youssef $S$ (2011) 1,25-Dihydroxyvitamin $\mathrm{D}(3)$ ameliorates Th17 autoimmunity via transcriptional modulation of interleukin-17A. Mol Cell Biol 31:3653-3669.

Kang Y, Xu L, Wang B, Chen A, Zheng G (2008) Cutting edge: immunosuppressant as adjuvant for tolerogenic immunization. $J$ Immunol 180:5172-5176.

Kang Y, Zhao J, Liu Y, Chen A, Zheng G, Yu Y, Mi J, Zou Q, Wang B (2009) FK506 as an adjuvant of tolerogenic DNA vaccination for the prevention of experimental autoimmune encephalomyelitis. $J$ Gene Med 11:1064-1070.

Kavousanaki M, Makrigiannakis A, Boumpas D, Verginis P (2010) Novel role of plasmacytoid dendritic cells in humans: induction of interleukin-10-producing Treg cells by plasmacytoid dendritic cells in patients with rheumatoid arthritis responding to therapy. Arthritis Rheum 62:53-63.

Khoo AL, Joosten I, Michels M, Woestenenk R, Preijers F, He XH, Netea MG, van der Ven AJ, Koenen HJ (2011) 1,25Dihydroxyvitamin D3 inhibits proliferation but not the suppressive function of regulatory $T$ cells in the absence of antigen-presenting cells. Immunology 134:459-468.

Korn T, Reddy J, Gao W, Bettelli E, Awasthi A, Petersen TR, Bäckström BT, Sobel RA, Wucherpfennig KW, Strom TB, Oukka M, Kuchroo VK (2007) Myelin-specific regulatory T cells accumulate in the CNS but fail to control autoimmune inflammation. Nat Med 13:423-431. 
Krementsov DN, Teuscher C (2013) Environmental factors acting during development to influence MS risk: insights from animal studies. Mult Scler 19:1684-1689.

Lemire JM, Archer DC (1991) 1,25-Dihydroxyvitamin D3 prevents the in vivo induction of murine experimental autoimmune encephalomyelitis. J Clin Invest 87:1103-1107.

Levy Barazany $H$, Barazany $D$, Puckett L, Blanga-Kanfi S, Borenstein-Auerbach N, Yang K, Peron JP, Weiner HL, Frenkel D (2014) Brain MRI of nasal MOG therapeutic effect in relapsingprogressive EAE. Exp Neurol 255:63-70.

Leyssens C, Verlinden L, Verstuyf A (2014) The future of vitamin D analogs. Front Physiol 5:122.

Lin R, Charlesworth J, van der Mei I, Taylor BV (2012) The genetics of multiple sclerosis. Pract Neurol 12:279-288.

Lucchinetti C, Brück W, Parisi J, Scheithauer B, Rodriguez M, Lassmann H (2000) Heterogeneity of multiple sclerosis lesions: implication for the pathogenesis of demyelination. Ann Neurol 47:707-717.

Luchtman DW, Ellwardt E, Larochelle C, Zipp F (2014) IL-17 and related cytokines involved in the pathology and immunotherapy of multiple sclerosis: current and future developments. Cytokine Growth Factor Rev 25:403-413.

Majewska M, Zajac K, Srebro Z, Sura P, Ksiazek L, Zemelka M, Szczepanik M (2007) Epicutaneous immunization with myelin basic protein protects from the experimental autoimmune encephalomyelitis. Pharmacol Rep 59:74-79.

Mannie MD, Blanchfield JL, Islam SM, Abbott DJ (2012) Cytokineneuroantigen fusion proteins as a new class of tolerogenic, therapeutic vaccines for treatment of inflammatory demyelinating disease in rodent models of multiple sclerosis. Front Immunol 3:255.

Mosayebi G, Ghazavi A, Ghasami K, Jand Y, Kokhaei P (2011) Therapeutic effect of vitamin D3 in multiple sclerosis patients. Immunol Invest 40:627-639.

Rahimi A, Faizi M, Talebi F, Noorbakhsh F, Kahrizi F, Naderi N (2015) Interaction between the protective effects of cannabidiol and palmitoylethanolamide in experimental model of multiple sclerosis in C57BL/6 mice. Neuroscience 290:279-287.

Segovia-Gamboa N, Rodríguez-Arellano ME, Rangel-Cruz R, Sánchez-Díaz M, Ramírez-Reyes JC, Faradji R, GonzálezDomínguez É, Sánchez-Torres C (2014) Tolerogenic dendritic cells induce antigen-specific hyporesponsiveness in insulin- and glutamic acid decarboxylase 65-autoreactive T lymphocytes from type 1 diabetic patients. Clin Immunol 154:72-83.

Smigiel KS, Srivastava S, Stolley JM, Campbell DJ (2014) Regulatory T-cell homeostasis: steady-state maintenance and modulation during inflammation. Immunol Rev 259:40-59.
Sospedra M, Martin R (2005) Immunology of multiple sclerosis. Annu Rev Immunol 23:683-747.

Spach KM, Nashold FE, Dittel BN, Hayes CE (2006) IL-10 signaling is essential for 1,25-dihydroxyvitamin D3-mediated inhibition of experimental autoimmune encephalomyelitis. J Immunol 177:6030-6037.

Taher YA, van Esch BC, Hofman GA, Henricks PA, van Oosterhout AJ (2008) 1alpha,25-dihydroxyvitamin D3 potentiates the beneficial effects of allergen immunotherapy in a mouse model of allergic asthma: role for IL-10 and TGF-beta. J Immunol 180:5211-5221.

Takeda M, Yamashita T, Sasaki N, Nakajima K, Kita T, Shinohara M, Ishida T, Hirata K (2010) Oral administration of an active form of vitamin D3 (calcitriol) decreases atherosclerosis in mice by inducing regulatory $T$ cells and immature dendritic cells with tolerogenic functions. Arterioscler Thromb Vasc Biol 30:2495-2503.

Tseveleki V, Tselios T, Kanistras I, Koutsoni O, Karamita M, Vamvakas SS, Apostolopoulos V, Dotsika E, Matsoukas J, Lassmann H, Probert L (2015) Mannan-conjugated myelin peptides prime non-pathogenic Th1 and Th17 cells and ameliorate experimental autoimmune encephalomyelitis. Exp Neurol 267:254-267.

Van Brussel I, Lee WP, Rombouts M, Nuyts AH, Heylen M, De Winter BY, Cools N, Schrijvers DM (2014) Tolerogenic dendritic cell vaccines to treat autoimmune diseases: can the unattainable dream turn into reality? Autoimmun Rev 13:138-150.

Viglietta V, Beacher AC, Weiner HL, Hafler DA (2004) Loss of functional suppression by $\mathrm{CD} 4+\mathrm{CD} 25+$ regulatory $\mathrm{T}$ cells in patients with multiple sclerosis. J Exp Med 199:971-979.

Wang TT, Nestel FP, Bourdeau V, Nagai Y, Wang Q, Liao J, TaveraMendoza L, Lin R, Hanrahan JW, Mader S, White JH (2004) Cutting edge: 1,25-dihydroxyvitamin D3 is a direct inducer of antimicrobial peptide gene expression. J Immunol 173:2909-2912.

Weber MS, Prod'homme T, Youssef S, Dunn SE, Steinman L,, Zamvil SS > (2014) Neither T-helper type 2 nor Foxp3+ regulatory $T$ cells are necessary for therapeutic benefit of atorvastatin in treatment of central nervous system autoimmunity. J Neuroinflammation 11:29.

Zorzella-Pezavento SF, Chiuso-Minicucci F, França TG, Ishikawa LL, da Rosa LC, Colavite PM, Marques C, Ikoma MR, Silva CL, Sartori A (2014) Downmodulation of peripheral MOG-specific immunity by pVAXhsp65 treatment during EAE does not reach the CNS. J Neuroimmunol 268:35-42. 